\title{
Germinação e desenvolvimento inicial de plântulas de soja convencional e sua derivada transgênica RR em condições de estresse salino
}

\author{
Germination and initial development of soybean seedlings and their transgenic derivatives \\ in salt stress condition \\ Tereza Cristina de Carvalho $^{\mathrm{I}^{*}}$ Sibelle Santanna da Silva ${ }^{\mathrm{I}}$ Rosemeire Carvalho da Silva ${ }^{\mathrm{I}}$ \\ Maristela Panobianco ${ }^{\mathrm{I}}$
}

\section{RESUMO}

O Brasil destaca-se como um dos maiores produtores mundiais de soja transgênica, sendo sua produção estendida principalmente a regiões com solos salinos, onde há acúmulo de sais que interferem na germinação da semente e no desenvolvimento das plântulas. O objetivo da pesquisa foi avaliar o efeito do estresse salino sobre a germinação e o desenvolvimento inicial de plântulas de soja convencional $e$ sua derivada transgênica Roundup Ready (RR), submetidas a diferentes condições de salinidade. Para tanto, utilizaram-se dois lotes de sementes de soja (CD 206 e CD 206 RR), sendo que os tratamentos constaram dos seguintes níveis de $\mathrm{NaCl}$ : zero; 5; 15; 30; 60 e 120 mmol $\mathrm{L}^{-1}$. A avaliação da qualidade fisiológica das sementes foi obtida pelos testes de germinação, comprimento de raiz e plântulas, massa seca de plântulas e volume radicular. $O$ estresse salino reduz a germinação das sementes de ambos os genótipos, sendo que o desenvolvimento de plântulas do genótipo transgênico RR é menos sensível em condições de maior salinidade (60 a 120mmol $\mathrm{L}^{-1}$ de $\mathrm{NaCl}$ ).

Palavras-chave: Glycine max, salinidade, qualidade fisiológica.

\section{ABSTRACT}

Brazil stands out as the largest worldwide producer of transgenic soybeans and has extended its production mainly to regions with saline soils, where there is accumulation of salts that interferes in seed germination and seedling development. The object of this research was to evaluate the effect of saline stress on the germination and initial development of soybean conventional seedling and its transgenic derivatives Roundup Ready (RR) submitted to different salinity conditions. For that purpose two lots of soybean seeds were used (CD 206 and CD 206 RR), the treatments consisted of the following levels of NaCl: 0, 5, 15, 30, 60 and $120 \mathrm{mmol} \mathrm{L}^{-1}$. The evaluation of physiological seed quality was obtained by germination test, root and seedling length, seedling dry mass and volume of roots. The salt stress reduced germination of seeds of both genotypes, and the development of seedling of genotype transgenic $R R$ is less sensitive in conditions of greater salinity (60 to $120 \mathrm{mmol} \mathrm{L}^{-1}$ of $\mathrm{NaCl}$ ).

Key words: Glycine max, salinity, physiological quality.

\section{INTRODUÇÃo}

Com o avanço da fronteira agrícola, a soja está cada vez mais ocupando áreas que antes eram cultivadas com outras espécies, especialmente na região Nordeste do Brasil, caracterizada por possuir a maior concentração de solos salinos do país (GHEYI \& FAGERIA, 1997). Solos com alta concentração de sais, além de prejudicar as plantas, pela diminuição da disponibilidade hídrica, causam toxidez iônica pelo acúmulo de íons nas células (como $\mathrm{Na}$ e $\mathrm{Cl}$ ), desequilíbrio nutricional ou inativação fisiológica de íons essenciais (VERSLUES et al., 2006).

O Brasil destaca-se mundialmente pelo acelerado crescimento de novas áreas com cultivo de transgênicos (ISAAA, 2010), podendo ser ressaltadas as regiões produtoras de soja Roundup Ready, que constitui a planta transgênica mais produzida no país. A soja RR é obtida por meio de técnicas da engenharia genética, sendo manipulada para ser resistente à

IDepartamento de Fitotecnia e Fitossanitarismo (DFF), Universidade Federal do Paraná (UFPR), R. dos Funcionários, 1540, 80035-050, Curitiba, PR, Brasil. E-mail: tcdcarva@gmail.com *Autor para correspondência. 
aplicação do herbicida glifosato. Dentre as vantagens do cultivo desses materiais, cita-se a facilidade de manejo de áreas infestadas com plantas daninhas (LEITÃO et al., 2008).

Em estudo divulgado pela Associação Brasileira de Sementes e Mudas - ABRASEM, estimase economizar, em período de 10 anos com adoção da soja transgênica RR, aproximadamente, 42,7 bilhões de litros de água e redução do consumo de 305 milhões de litros de óleo diesel, quantias essas suficientes para o consumo, respectivamente, de 100 mil habitantes e abastecimento de uma frota de 127,1 mil veículos (ABRASEM, 2008).

Atualmente, as áreas de expansão do cultivo da soja coincidem com as regiões de solos salinos, devido ao baixo índice pluviométrico, déficit hídrico elevado e deficiências naturais de drenagem (DIAS et al., 2007), além do uso inadequado de água salina na irrigação (SANTANA et al., 2003) e superdosagem de fertilizantes (ELOI et al., 2011). Nessas regiões, a baixa disponibilidade hídrica constitui-se o principal fator limitante para a germinação das sementes, visto que a água é fundamental para a embebição e reativação dos processos metabólicos do embrião, permitindo o crescimento do eixo embrionário (MARCOSFILHO, 2005).

Estudos direcionados ao comportamento das plantas em solos salinos são ferramentas úteis aos produtores, pois, conforme destacaram SANTOS et al. (1996), a capacidade de germinação das sementes de soja em ambientes salinos está ligada à constituição genética do material. Assim, o comportamento de diferentes espécies agrícolas, como soja (SANTOS et al., 1996; CATUCHI et al., 2011), arroz (ROSHANDEL, 2007) e milho (AZEVEDO NETO \& TABOSA, 2000; CONUS et al., 2009), tem sido objeto de estudo em diferentes condições de estresses ambientais, com destaque para o estresse salino e hídrico, visto que esses ambientes são cada vez mais frequentes na agricultura.

Tem se observado que há carência de trabalhos que abordem o comportamento de organismos geneticamente modificados, como a soja $\mathrm{RR}$, frente às adversidades do ambiente, principalmente com relação à salinidade do solo. Segundo MENEGATTI \& BARROS (2007), a alteração do genoma pode levar a planta modificada a apresentar um comportamento não observado no organismo original. Informações sobre essas alterações são relevantes para o avanço da ciência e tecnologia, bem como para subsidiar a escolha de materiais mais adaptados a diferentes ambientes de produção.

Nesse sentido, o trabalho teve como objetivo avaliar o efeito do estresse salino sobre a germinação e desenvolvimento inicial de plântulas de soja convencional e sua derivada transgênica Roundup Ready (RR), em diferentes condições de salinidade.

\section{MATERIAL E MÉTODOS}

A pesquisa foi conduzida no Laboratório de Análise de Sementes do Departamento de Fitotecnia e Fitossanitarismo, da Universidade Federal do Paraná, em Curitiba - PR, com sementes de soja da cultivar 'CD206' e sua derivada transgênica 'CD206 RR', produzidas na safra 2009/10.

As amostras de sementes foram previamente homogeneizadas em um divisor centrífugo (BRASIL, 2009) e separadas conforme o tamanho, utilizando-se sementes retidas em peneiras de crivo circular 7,0mm, que foram armazenadas em sacos de papel do tipo Kraft, em ambiente controlado, durante todo período experimental.

Para a caracterização da qualidade inicial das sementes, determinou-se o teor de água e realizou-se o teste de germinação de acordo com a metodologia proposta por BRASIL (2009), utilizando-se duas subamostras de 5 gramas para determinação do teor de água e quatro subamostras de 50 sementes para o teste de germinação por cultivar (Tabela 1).

Para a composição dos tratamentos, as sementes foram semeadas em substrato papel (tipo Germitest), umedecidos com quantidade equivalente a 2,5 vezes a massa do substrato seco, com solução de cloreto de sódio $(\mathrm{NaCl})$ nos seguintes níveis: zero (referente à testemunha, na qual se utilizou água destilada); 5; 15; 30; 60 e 120mmol L-1 de $\mathrm{NaCl}$, correspondendo aos seguintes valores de condutividade elétrica (CE): 0,08; 0,55; 1,41; 2,71; 5,04 e 9,53dS $\mathrm{m}^{-1}$, respectivamente, medidos em condutivímetro Marca Hayonik ${ }^{\circledR}$, modelo FTP 905.

Os tratamentos simulando o estresse salino foram definidos a partir da solução de $\mathrm{NaCl}$ determinada por FERNANDES etal.(2002)epor NEVES etal.(2004). De acordo com a EMBRAPA(1999), o caráter salino do solo na

Tabela 1 - Dados médios iniciais obtidos para determinação do teor de água e teste de germinação de sementes de soja das cultivares 'CD 206' vs 'CD 206 RR'.

\begin{tabular}{lcc}
\hline Cultivar & Teor de água (\%) & Germinação (\%) \\
\hline 'CD 206' & 11,5 & 86 a \\
'CD206 RR' & 11,5 & 86 a \\
CV (\%) & - & 4,2 \\
\hline
\end{tabular}

Médias seguidas pela mesma letra na coluna não diferem entre si pelo teste de Tukey $(\mathrm{P} \leq 0,01)$. 
$\mathrm{CE} \mathrm{a} 25^{\circ} \mathrm{C}$ é maior ou igual a quatro e menor que $7 \mathrm{dS} \mathrm{m}^{-1}$, enquanto o caráter sálico é maior ou igual a $7 \mathrm{dS} \mathrm{m}^{-1}$.

Para o teste de germinação, utilizaram-se quatro subamostras de 50 sementes por tratamento, distribuídas em rolos de papel toalha umedecidos com água destilada, em quantidade equivalente ao volume de 2,5 vezes a massa do papel seco e mantidas em germinador regulado a temperatura de $25^{\circ} \mathrm{C}$ no regime de luz constante. A contagem de plântulas normais foi realizada no sexto dia após semeadura (BRASIL, 2009) e os resultados foram expressos em porcentagem média de plântulas normais para cada tratamento e cultivar.

O comprimento de plântulas foi avaliado segundo procedimento descrito por NAKAGAWA (1999), realizando-se a medição de toda a plântula, partindo do meristema apical até a extremidade da raiz primária, enquanto o comprimento de raiz foi obtido medindo-se desde a base do hipocótilo até a extremidade da raiz primária. Para tanto, utilizaram-se, em cada tratamento, quatro repetições de 10 sementes, cujas medições foram efetuadas no oitavo dia após a semeadura, com auxílio de uma régua milimetrada, sendo os resultados expressos em centímetros.

Também foram avaliados a massa seca de plântula e o volume radicular, seguindo o mesmo procedimento para instalação do teste de comprimento de plântula (NAKAGAWA, 1999). Para a determinação da massa seca, as plântulas normais tiveram seus cotilédones extraídos e foram acondicionadas em estufa a $60^{\circ} \mathrm{C}$ até obtenção de peso constante. $\mathrm{Na}$ avaliação do volume radicular, os sistemas radiculares das plântulas normais foram extraídos, submetidos à leitura ótica com scanner e analisados pelo programa "Win Mac Rhizo", com os resultados expressos em mg e $\mathrm{cm}^{3}$, respectivamente.

Os resultados foram submetidos à análise de variância pelo teste $\mathrm{F}(\mathrm{P}<0,01)$ e de regressão, sendo os modelos escolhidos com base no coeficiente de determinação e na sua significância; utilizou-se o sistema de análise para microcomputadores ASSISTAT. Os dados iniciais obtidos no teste de germinação não foram transformados e suas médias foram comparadas pelo teste de Tukey $(\mathrm{P} \leq 0,01)$.

\section{RESULTADOS E DISCUSSÃO}

A análise inicial da qualidade fisiológica e do teor de água das sementes, para ambos os genótipos, não indicou diferenças significativas $(\mathrm{P} \leq 0,01)$ (Tabela 1). Na avaliação do efeito do estresse salino entre as cultivares, a uniformização da umidade das sementes foi imprescindível para a confiabilidade dos resultados (MARCOS FILHO, 2005), ocorrendo o mesmo para os resultados obtidos no teste de germinação (Tabela 1). Este fato se faz importante, pois, para a comparação de diferentes genótipos, é necessário similaridade quanto a sua qualidade fisiológica inicial.

A salinidade do substrato afetou a germinação das sementes de ambos os genótipos (Figura 1A), sendo que este efeito na cultivar convencional iniciou-se a partir de $30 \mathrm{mmol} \mathrm{L}^{-1}$ de $\mathrm{NaCl}$, estando as sementes com germinação acima do padrão para comercialização (80\%) até o nível de $60 \mathrm{mmol} \mathrm{L}^{-1}$ de $\mathrm{NaCl}$, com pequena redução em relação ao seu potencial fisiológico inicial (Tabela 1). Ao avaliarem lotes de sementes de soja de qualidade fisiológica distinta, MORAES \& MENEZES (2003) observaram que, à medida que houve redução do potencial osmótico, a germinação foi reduzida de maneira drástica $(<20 \%)$. Esses resultados eram esperados, pois o estresse salino atua com efeito osmótico ou iônico, prejudicando a absorção de água ou favorecendo a entrada de íons nas células (BRACCINI et al., 1996).

Para sementes do genótipo transgênico RR, a germinação se manteve acima de $80 \%$ somente até $15 \mathrm{mmol} \mathrm{L}^{-1}$ de $\mathrm{NaCl}$ (Figura 1A); em situações de maior salinidade, a redução do poder germinativo das sementes foi ainda mais drástica, sendo bastante afetado em condições de caráter sálico $\left(120 \mathrm{mmol} \mathrm{L}^{-1}\right.$ de $\mathrm{NaCl}$ ), pois a restrição hídrica torna-se maior em função do acúmulo de íons de sais de sódio e cloro na região da rizosfera.

À medida que se elevou a salinidade do substrato, houve diminuição no comprimento de plântulas de ambos os genótipos até salinidade de $30 \mathrm{mmol} \mathrm{L}^{-1} \mathrm{NaCl}$ (Figura 1B), por outro lado, ocorreu estabilização na diminuição do comprimento de plântulas para o genótipo transgênico RR a partir de $30 \mathrm{mmol} \mathrm{L}^{-1}$, voltando a decrescer na condição sálica (120mmol L-1). Para a soja convencional, o comprimento de plântula (Figura 1B) diminuiu $(\mathrm{P} \leq 0,01)$ em função do aumento da salinidade do substrato, permitindo o ajuste a uma regressão linear negativa. Tais resultados estão de acordo com TAIZ \& ZEIGER (2004), que relataram que a exposição das plântulas a valores crescentes de salinidade contribui para menores taxas de crescimento.

O comportamento distinto entre os genótipos pode ser melhor visualizado ao se avaliar o volume (Figura 1C) e o comprimento de raiz das plântulas (Figura 1D), uma vez que, para a soja transgênica, constatou-se estabilização no desenvolvimento a partir de $60 \mathrm{mmol} \mathrm{L}^{-1}$ de $\mathrm{NaCl}$, ou seja, nessa condição de ambiente, o material transgênico RR obteve melhor reação frente à situação de estresse, passando a investir as reservas da semente 


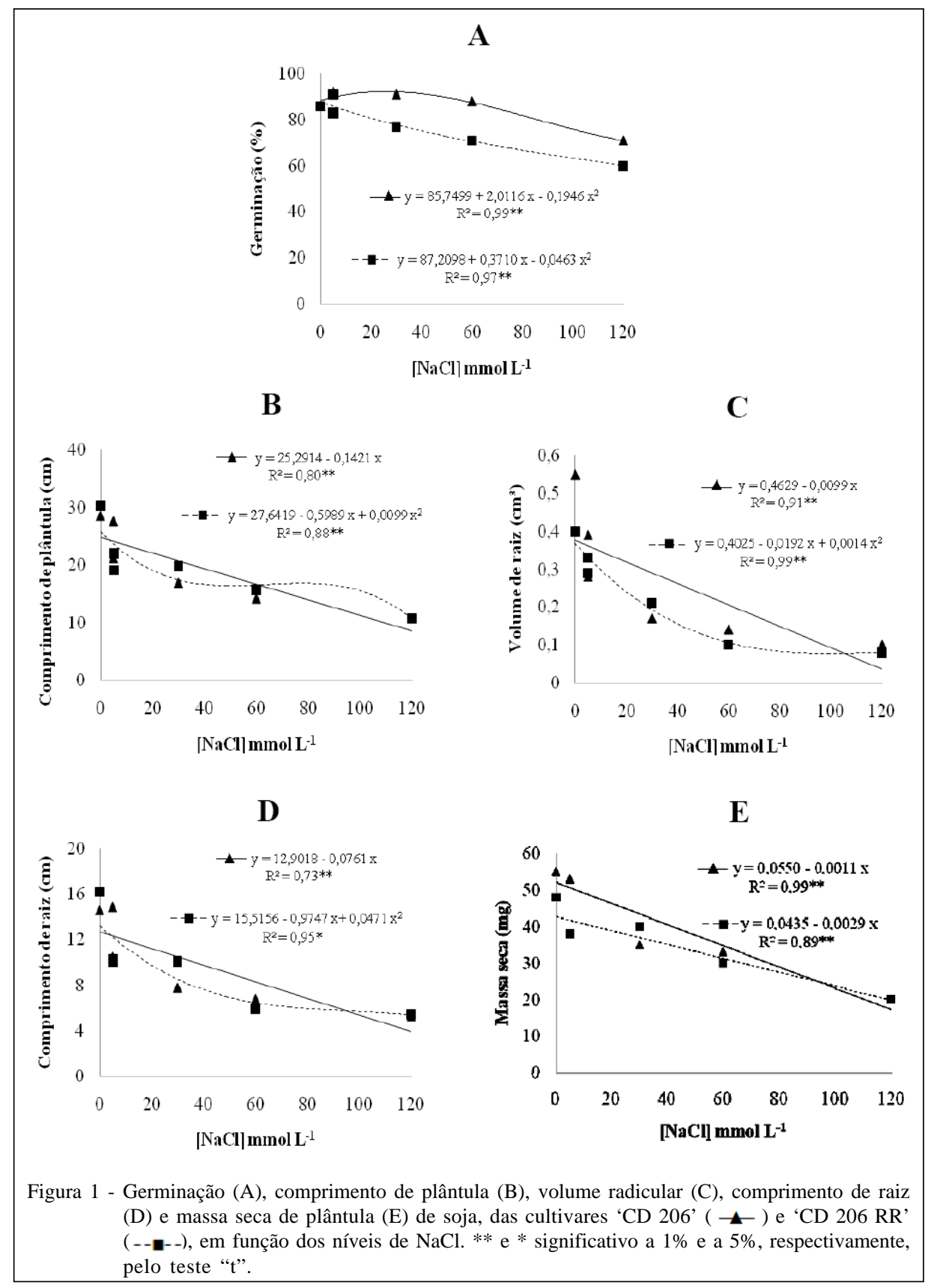

no crescimento da raiz primária, no intuito de ampliar a região de captação de água. Resultados similares foram obtidos por AZEVEDO NETO \& TABOSA(2000), que verificaram maior sensibilidade à salinidade no crescimento da parte aérea de plantas de milho, enquanto as raízes mantiveram seu desenvolvimento.

Para as plantas com maior expansão do sistema radicular, há tendência de serem mais resistentes ao efeito do estresse hídrico, uma vez que a regulação da expansão foliar durante o período de exposição ao estresse osmótico ocorre em função da quantidade de água presente nas raízes (TOORCHI et al., 2009), proporcionando condições para o desenvolvimento da planta.

O comprimento de plântulas (Figura 1B), volume (Figura 1C) e comprimento de raiz (Figura 1D) decresceu linearmente com o aumento da salinidade, sendo mais afetado na condição de caráter sálico (120 $\mathrm{mmol} \mathrm{L}^{-1}$ de $\mathrm{NaCl}$ ), proporcionando os menores coeficientes $\left(0,80^{* *}, 0,91^{* *}\right.$ e $0,73^{* *}$, respectivamente), 
uma vez que esse material tem maior sensibilidade a teores mais elevados de íons de sais.

A paralisação no crescimento das plantas, provocado pelo sal, se deve ao custo metabólico de energia que elas necessitam para se adaptarem a salinidade (RICHARDSON \& McCREE, 1985). Desse modo, a menor sensibilidade do genótipo transgênico mediante a maiores níveis de salinidade (acima de $60 \mathrm{mmol} \mathrm{L}^{-1}$ de $\mathrm{NaCl}$ ) pode estar associada à manutenção da pressão osmótica, que, segundo TAL (1985), é obtida por meio do acúmulo de solutos inorgânicos no vacúolo e orgânicos no citoplasma.

Os resultados obtidos para a massa seca de plântulas de ambos os genótipos (Figura 1E) foram semelhantes, havendo redução linear no desenvolvimento de plântulas à medida que os níveis de salinidade foram elevados, indicando que não houve maior ganho de massa seca nas plântulas para ambos os genótipos, mas sim adequação na distribuição das reservas da semente para os tecidos. De forma semelhante, ALARCON et al. (1994) eAZEVEDO NETO \& TABOSA (2000) também observaram que a taxa de expansão celular e produção de massa seca foi mais afetada em condições de alta salinidade, nas culturas do tomate e milho, respectivamente.

Nesse sentido, verificou-se que, durante o processo de germinação das sementes de soja convencional e sua derivada transgênica RR, os genótipos foram mais afetados à medida que a salinidade aumentou. Entretanto observou-se que, durante o crescimento de plântulas do genótipo transgênico, estas passaram a investir no sistema radicular quando as condições de estresse foram mais elevadas (a partir de $60 \mathrm{mmol} \mathrm{L}^{-1} \mathrm{de} \mathrm{NaCl}$ ), enquanto na soja convencional houve diminuição linear no comprimento de plântula, raiz e volume. Por outro lado, a massa seca das plântulas de ambos os genótipos se mantiveram similares, evidenciando que houve diferença na distribuição das reservas das sementes entre os genótipos avaliados.

As plântulas tendem a direcionar suas reservas para o desenvolvimento radicular à medida que seus tecidos passam por estresses salino ou hídrico, sendo este um mecanismo adaptativo da planta às adversidades do ambiente em que está inserida (TAIZ \& ZEIGER, 2004); dessa forma, pode-se inferir que essas adaptações determinam o melhor ou pior desempenho dos organismos frente a um estresse ambiental.

\section{CONCLUSÃO}

O estresse salino reduz a germinação das sementes de ambos os genótipos.
O desenvolvimento de plântulas do genótipo transgênico RR é menos sensível em condições de maior salinidade (60 a $120 \mathrm{mmol} \mathrm{L}^{-1}$ de $\mathrm{NaCl}$ ).

\section{REFERÊNCIAS}

ABRASEM (Associação Brasileira de Sementes e Mudas). Impacto dos transgênicos. Seed News, ano XII, n.2, p.38-38, 2008.

ALARCON, J.J. et al. Growth and osmotic adjustment of two tomato cultivars during and after saline stress. Plant and Soil, v.166, n.1, p.75-82, 1994. Disponível em: <http:// www.springerlink.com/content/x7102584257j443x/>. Acesso em: 27 jun. 2011. doi: 10.1007/BF02185483.

AZEVEDO NETO, A.D.; TABOSA, J.N. Estresse salino em plântulas de milho: parte I análise do crescimento. Revista Brasileira de Engenharia Agrícola Ambiental, v.4, n.2, p.159-164, 2000. Disponível em: <http://www.agriambi.com.br/ revista/v4n2/159.pdf>. Acesso em: 8 jun. 2011. doi:10.1590/ S1415-43662000000200006.

BRACCINI, A.L. et al. Germinação e vigor de sementes de soja sob estresse hídrico induzido por soluções de cloreto de sódio, manitol e polietilenoglicol. Revista Brasileira de Sementes, v.18, n.1, p.10-16, 1996. Disponível em: <http:// www.abrates.org.br/revista/artigos/1996/v18n1/artigo03.pdf>. Acesso em: 11 jun. 2011.

BRASIL. Ministério da Agricultura, Pecuária e Abastecimento. Regras para Análise de Sementes. Brasília: Secretaria de Defesa Agropecuária, MAPA/ACS, 2009. 39p.

CATUCHI, T.A. et al. Tolerance to water deficiency between two soybean cultivars: transgenic versus conventional. Ciência Rural, v.41, n.3, p.372-378, 2011. Disponível em: <http:// www.scielo.br/pdf/cr/v41n3 /a902cr4161.pdf>. Acesso em: 20 jun. 2001. doi: 10.1590/S0103-84782011000300002.

CONUS, L.A. et al. Germinação de sementes e vigor de plântulas de milho submetidas ao estresse salino induzido por diferentes sais. Revista Brasileira de Sementes, v.31, n.4, p.67-74, 2009. Disponível em: <http://www.scielo.br/scielo.php?script=sci_arttext\&pid=S0101$31222009000400008 \&$ lang=pt $\geq$. Acesso em: 10 abr. 2011. doi: 10.1590/S0101-31222009000400008.

DIAS, N.S. et al. Salinização do solo por aplicação de fertilizantes em ambiente protegido. Irriga, v.12, n.1, p.135-143, 2007. Disponível em: $<$ http://200.145.140.50/ojs1/ viewarticle.php?id=220\&layout=abstract $>$. Acesso em: 10 abr. 2011.

ELOI, W.M. et al. Influência de diferentes níveis de salinidade nas características sensoriais do tomate. Revista Brasileira de Engenharia Agrícola e Ambiental, v.15, n.1, p.16-21, 2011. Disponível em: <http://www.scielo.br/pdf/rbeaa/v15n1/ a03v15n01.pdf $>$. Acesso em: 10 abr. 2011. doi: 10.1590/ S1415-43662011000100003.

EMBRAPA. Centro Nacional de Pesquisa de Solos. Sistema brasileiro de classificação de solos. Brasília: EmbrapaProdução de Informação; Rio de Janeiro: EMBRAPA Solos, 1999. 12p.

FERNANDES, A.R. et al. Nutrição mineral de mudas de pupunheira sob diferentes níveis de salinidade. Pesquisa 
Agropecuária Brasileira, v.37, n.11, p.1613-1619, 2002. Disponível em: <http://www.scielo.br/pdf/pab/v37n11/ 14527.pdf>. Acesso em: 5 abr. 2011. doi: 10.1590/S0100204X2002001100013.

GHEYI, H.R.; FAGERIA, N.K. Efeitos dos sais sobre as plantas. In: UNIVERSIDADE FEDERAL DA PARAÍBA. (Org.). Manejo e controle da salinidade na agricultura irrigada. Campina Grande: UFPB, 1997. p.125-131.

ISAAA (International Service for the Acquisition of Agri-biotech Applications). Global status of commercialized biotech / GM Crops. Nova York, 2010. 30p.

LEITÃO, F.O. et al. Transgênico ou convencional: o dilema da soja no Mato Grosso. In: CONGRESSO DA SOCIEDADE BRASILEIRA DE ECONOMIA, ADMINISTRAÇÃO E SOCIOLOGIA RURAL, 46., 2008, Rio Branco, Acre, Brasil. Anais... Rio Branco-Acre: Sociedade Brasileira de Economia, Administração e Sociologia Rural - SOBER, 2008. 19p.

MARCOS FILHO, J. Fisiologia de sementes de plantas cultivadas. Piracicaba: FEALQ, 2005. 495p.

MENEGATTI, A.L.A.; BARROS, A.L.M. Análise comparativa dos custos de produção entre soja transgênica e convencional: um estudo de caso para o Estado do Mato Grosso do Sul. Revista de Economia e Sociologia Rural, v.45, n.1, p.163-183, 2007. Disponível em: $<$ http://www.scielo.br/scielo.php?script=sci_arttext\&pid=S010320032007000100008>. Acesso em: 25 jun. 2011. doi: 10.1590/ S0103-20032007000100008.

MORAES, G.A.F.; MENEZES, N.L. Desempenho de sementes de soja sob condições diferentes de potencial osmótico. Ciência Rural, v.33, n.2, p.219-226, 2003. Disponível em: <http:// www.scielo.br/pdf/cr/v33n2/15209.pdf>. Acesso em: 14 maio, 2011. doi: 10.1590/S0103-84782003000200007.

NAKAGAWA, J. Testes de vigor baseados no desempenho das plântulas. In: KRZYZANOSKI, F.C. et al. (Ed.). Vigor de sementes: conceitos e testes. Londrina: ABRATES, 1999. Cap.2, p.1-24.

NEVES, O.S.C. et al. Crescimento e nutrição mineral de mudas de umbuzeiro (Spondias tuberosa Arr. Cam.) submetidas a níveis de salinidade em solução nutritiva. Ciência e Agrotecnologia v.28, n.5, p.997-1006, 2004. Disponível em: <http:// www.scielo.br/pdf/cagro/v28n5/v28n5a05.pdf>. Acesso em: 5 abr. 2011. doi: 10.1590/S1413-70542004000500005.
RICHARDSON, S.G.; McCREE, K.J. Carbon balance and water relations of sorghum exposed to salt and water stress. Plant Physiology, v.79, n.4, p.1015-1020, 1985. Disponível em: <http://www.ncbi.nlm.nih.gov/pmc/articles/PMC1075018/pdf/ plntphys00595-0099.pdf>. Acesso em: 7 jun. 2011. doi: 00320889/85/79/1015/06/\$01.00/0

ROSHANDEL, P. Xylem sap analysis reveals new facts of salt tolerance in rice genotypes. Brazilian Journal of Plant Physiology, v.19, n.3, p.185-192, 2007. Disponível em: <http:/ /www.scielo.br/scielo.php?script=sci_arttext\&pid=S167704202007000300002>. Acesso em: 9 jun. 2011. doi: 10.1590/ S1677-04202007000300002.

SANTANA, M.J. et al. Efeito da irrigação com água salina em solo cultivado com feijoeiro (Phaseolus vulgaris L.). Ciência e Agrotecnologia, v.27, n.2, p.443-450, 2003. Disponível em: <http://www.scielo.br/pdf/cagro/ v27n2/a27v27n2.pdf>. Acesso em: 12 abr. 2011. doi: 10.1590/S141370542003000200027 .

SANTOS, V.L.M. et al. Utilização de estresse salino na avaliação da qualidade das sementes de genótipos de soja (Glycine max L. Merrill). Revista Brasileira de Sementes, v.18, n.1, p.6372, 1996. Disponível em: <http://www.abrates.org.br/revista/ artigos/1996/v18n1/artigo11.pdf $>$. Acesso em: 21 maio, 2011.

TAIZ, L.; ZEIGER, E. Fisiologia vegetal. 3.ed. Porto Alegre: Artmed, 2004. 719p.

TAL, M. Genetics of salt tolerance in higher plants: theoretical and practical considerations. Plant and Soil, v.89, n.2, p.199226, 1985. Disponível em: <http://www.springerlink.com/ content/yv65868ru1381764/>. Acesso em: 6 jun. 2011. doi: 10.1007/BF02182243.

TOORCHI, M. et al. Proteomics approach for identifying osmotic-stress-related proteins in soybeans roots. Peptides, v.30, n.12, p.2108-2117, 2009. Disponível em: <http:// www.sciencedirect.com/science/article/pii/S019697810 9003647>. Acesso em: 28 ago. 2011. doi: 10.1016/ j.peptides.2009.09.006

VERSLUES, P.E. et al. Methods and concepts in quantifying resistance to drought, salt and freezing, abiotic stress that affect plant water status. Plant Journal, v.45, n.4, p.523-539, 2006. Disponível em: <http://www.ncbi.nlm.nih.gov/pubmed/ 16441347>. Acesso em: 6 jun. 2011. doi: 10.1111/j.1365313X.2005.02593.x. 